\title{
The Han Minzu, Fragmented Identities, and Ethnicity
}

\section{AGNIESZKA JONIAK-LÜTHI}

This paper focuses on the majority population in the People's Republic of China-the Hanand their various collective identities. The Han play a pivotal role in consolidating the Chinese territory and the multiethnic Chinese nation. Therefore, the governments in the twentieth century have invested substantial efforts in promoting a unitary Han identity. In spite of that, powerful local identities related to native place, occupation, and family histories persist. This essay traces these identities and analyzes their intertwinement. Further, it discusses the question of ethnicity of both the Han and local identity categories, and concludes that while Han enact ethnicity in their relations to other minzu, local identity categories are more social than ethnic. It further posits that moments of confrontation, "degree" of ethnicity, scales of categorization, and relationality of identities are notions that should be given particular attention in the studies of ethnicity in China and elsewhere.

$\mathrm{T}$ HE HAN minzu, ${ }^{1}$ translated variously as nationality or ethnic group, constitutes officially 91.5 percent of China's population. The Han are recognized by the state as the national majority and the core of the Chinese multiethnic nation. Besides the Han, the Chinese nation is comprised of many other minzu, including Zhuang, Mongols, Uyghur, Tibetans, and Hui, collectively referred to as "national minorities" (shaoshu minzu). Current representations of the Han as a national majority tend to reify them as a coherent group that has evolved through millennia to become the nation's core today. While scholars have demonstrated that the history of "the Han" is anything but linear, ${ }^{2}$ the Communist central governments have consistently represented them as a coherent, historically constituted community. In so doing, they have followed in the footsteps of early twentieth-century intellectuals and revolutionaries who were motivated by and spread a vision of the Han as a national community originating from one ancestor (the legendary Yellow Emperor) and forming one gigantic national

Agnieszka Joniak-Lüthi (joniak@anthro.unibe.ch) is Post-doctoral Researcher at the Institute of Social Anthropology, University of Bern.

${ }^{1}$ Minzu is a complex term that can be translated as "nation," "nationality," or "ethnic group," depending on the time and circumstances in which it is used. In China, there are fifty-six minzu that have been recognized by the state after the extensive Minzu Classification Project in the 1950s. The Han minzu constitutes 91.5 percent of the entire Chinese population and is thus the largest minzu.

${ }^{2}$ For examples see contributions by Mark Elliott, C. Patterson Giersch, and James Leibold in the recent Critical Han Studies volume (2012). 
lineage. ${ }^{3}$ The idea that the Han nation would become the backbone of the first postimperial state in China undergirded the nationalists' efforts in the Xinhai Revolution of 1911.

However, while "Han-ness" is still today a handy political category for nation- and state-making projects, it was not invented a century ago solely for nation-making purposes. Though highly unstable in its scope and meaning, it was also a meaningful identity in the pre-1911 period, widely utilized in negotiations on social positioning by those who identified with it in local as well as empire-wide contexts. Likewise, today its meaning and roles continue to extend beyond national politics.

This essay reflects on Han-ness by focusing on its fissures. Like much recent work on the Han, it counters the category's conceived homogeneity; to do so, I focus specifically on the fragmented local identities of those who have been classified by the state as Hanzu. ${ }^{4}$ Most of these local identity categories are related to native place or region of origin (e.g., as "natives of Shanghai," "natives of Henan," "Southerners"), or locality in general (as "locals" vs. "migrants"). My study is thus related to earlier research carried out by Honig (1992), Goodman (1995), Faure and Siu (1995), and Constable (1996), insofar as it draws attention to diversity of local identities. Yet, it also moves beyond this research by exploring the meanings of these local identities, the power dynamic that exists between local identities and the Han identity, and the politics that influences these negotiations.

Another objective of this paper is to explore the question of ethnicity. Are the Han an ethnic group? Are local identities ethnic too? I argue that it is crucial to put aside the term "ethnic group" and turn first to local terms as categories of analysis. These will allow us to see the complex networks of relationships that link these identities in local contexts and to explore the question of ethnicity from the perspective of their relationality.

Unlike many other studies of the Han, which draw on historical sources and other written materials to trace the ethno-genesis of the category and its fragmented histories, this study is based on ethnographic interviews and observation, and focuses on contemporary Han. My analysis is based on ninety-one interviews I carried out in the winter of 2003 in Beijing and Shanghai, and on my observations from numerous research trips in the People's Republic of China (PRC) since 1996. During these fieldwork trips, I was often struck by the vivid presence of local identities and by the importance the Han attached to them. My research interests developed from so many conversations and observations, and I came to focus on the meaning and roles of minzu identity on the one hand and of local identities on the other. During the interviews, I inquired about names (under "names" I understand in this paper mainly socionyms and thus use these two terms interchangeably) for local identity categories and their stereotypical characteristics and associations. My informants also discussed with me the "pairs of opposition" the categories formed (e.g., Southerners vs. Northerners, urban Han vs. rural Han). In the

\footnotetext{
${ }^{3}$ For detailed analyses of this process, see Duara (1995), Chow (2001), Leibold (2006), and Harrison (2001). See also Rhoads (2000) for an analysis that draws on the perspective of Manchu-Han relations. Finally, Gladney (1994) draws attention to the importance of the Minzu Recognition Project in the 1950s in the making of the Hanzu.

${ }^{4} \mathrm{Hanzu}$ is a corruption of the compound Han minzu. Hanzu are the members of the Han minzu.
} 
section below, I introduce the factors that led me to focus on names and stereotypes, and on the methodologies that connect them to broader anthropological research on categorization and identity.

\section{Functions of Stereotypes and Names}

Naming and stereotyping "us" and "them" are inherent parts of the processes of categorization and reification, both of which are intimately bound to social positioning and power distribution. Stereotypes and names (socionyms, ethnonyms, and nationyms) arise during the processes of self- and other-identification. In that sense, they are a universal part of social, ethnic, and national categorization and boundary-making processes. Bourdieu (1991, 240) points out that names of groups "record a particular stage of struggles and negotiations over the official designations and the material and symbolic advantages associated with them." Moreover, he argues that agents will "resort to practical and symbolic strategies aimed at maximizing the symbolic profit of naming” (240). I believe a similar struggle over symbolic resources associated with names takes place as well in the unofficial spaces between competing social and ethnic categories. The identity labels "native of Beijing" or "native of Shanghai" are proudly enacted, as they connote political centrality and economic advancement. On the other hand, labels like "Sichuan rats" or "Henan vagabonds," associated with migrants from two impoverished and overpopulated provinces, will be employed by others to generate and reify certain social hierarchies of local identity categories.

Similarly to naming, the aim of stereotyping is to construct and objectify certain social orders and social relations. This aim is achieved when the actors begin to recognize vague differences as significant and crucial, or when they believe differences exist where there are in fact none (Tajfel 1969, 82; compare Barth [1969] 1996). Accordingly, although differences between, for instance, "natives of Beijing" and "natives of Shanghai" may not be apparent, the collected stereotypes reveal powerful beliefs that the two categories differ diametrically and thoroughly. Hence, stereotypes and names possess reifying and naturalizing functions. They are both instruments and effects of complex power struggles.

Stereotypes are based on the belief that all members of a given category are alike, homogeneous, and predictable on the basis of their membership in that category (Oakes, Haslam, and Turner 1994, 102). Yet, they are not fixed, final images. When the sociopolitical frame changes, new stereotypes will gradually come into being. The competition-focused theories argue that stereotypes are strategic devices employed in certain contexts by individuals, as well as social, ethnic, or national groupings to achieve certain ends. Thus, they are tightly bound to questions of power and social positioning. In the 1960s, Sherif $(1967,152)$ suggested that stereotypes should be understood as products of competition between social groups over material resources. A number of scholars later extended his argument to include the competition over symbolic resources (Tajfel et al. 1971, 172), arguing that "[s]tatus, self-esteem and beliefs override objective benefits in importance” (Leyens, Yzerbyt, and Schadron 1994, 52-53). While I find the notions of status and self-esteem crucial to stereotyping, they significantly do not explain the not uncommon cases where members of a category hold negative stereotypes of 
themselves while maintaining positive ones of others. As a response to competitionfocused theories' inability to explain the phenomenon of negative self-stereotyping, Jost and Banaji (1994) suggest yet another function of stereotypes as devices that maintain the existing status quo, even at the expense of a group's or one's personal interest.

Stereotypes are thus employed to naturalize social, ethnic, and national constructs; to reify social status quos; to justify existing relationships within social, ethnic, or national systems; and also to meaningfully (to the actors) explain social processes and events (Hoffman and Hurst 1990, 206; Jost and Banaji 1994, 20; Tajfel 1981). The justificative function refers to the phenomenon of ascribing specific stereotypes to a group to justify certain behaviors and attitudes towards it; for example, "natives of Subei" are discriminated against on the eastern Chinese job market due to their reported "backwardness" and "dishonesty." Moreover, stereotypes function also as "causal explanators," allowing for a subjectively meaningful understanding of events through stereotype-based identification of responsible actors. Accordingly, the business success of an individual from Zhejiang Province is surely to be ascribed to the reported "natural business talent" of "natives of Zhejiang." Hence, stereotypes as well as names are subjectively accurate, subjectively meaningful representations of social, ethnic, and national categories and relations between them. They reflect and order the worldview of the persons and groups that reproduce them, shrouding their logics of action and argumentation in an aura of seemingly obvious, universal conclusions (Oakes and Reynolds 1997, 64, 70; Spears et al. 1997, 5).

In the present study, I focus on the stereotypes and names ascribed to local identity categories of the people classified officially as Han. First of all, the collected names and stereotypes signal what sort of local identity categories are socially significant and meaningful. They also indicate what boundaries fragment the imagined category of the Hanzu classification. Further, I briefly identify from the research material the ways in which my informants draw on these names and stereotypes to position themselves and others in the hierarchies of power that exist among the Hanzu. Finally, the meaning of stereotypes and names offers us a glimpse into topics that matter in the differentiation between various local identity categories.

\section{Native Place and Identity}

The majority of names and stereotypes I collected during interviews referred to locality-bound identity categories, woven around the concept of native place. Hence, it is essential to here focus briefly on the identification with native place. A significant number of interviewees pointed to the "native-place-determined mindset" (jiaxiang guannian), basically the notion that people originating in one native place are imbued with the same "essence" that makes them bound to it and similar to each other, as the main principle guiding the Han idea of diversity. Both Chinese and Western scholars widely agree that native place bonds play an important role in the ways Han identify themselves and others. Several studies have discussed the role native place bonds play in the economic, social, and ethnic organization and differentiation among the Han (see Fei 1992; Giersch 2012; Gladney 1998; Goodman 1995; Ho 1966; Honig 1992; Leong 1997; Liu 2003; Naquin and Rawsky 1987; J. Watson 1988; Yi 2002). 
The key concepts in this discourse of native place are jiaxiang, guxiang, and jiguan. The first two terms, jiaxiang and guxiang, have a similar meaning: "hometown" or "native place." The latter of the two also means "birthplace." The concepts of jiaxiang and guxiang are more flexible and individual-oriented than the third term, jiguan. Ji here refers to "record," "registry," or "register," while guan means "being linked together," or "following in the continuous line." Although jiguan could be translated as one's native place too, it rather refers to the locality identified as ancestral land along the patriline, the place where the family's name comes from and where, especially in southern China, the ancestral hall is located.

Fei Xiaotong (1992, 121-27) argued that the Han bond with a place, and more broadly with a region of origin, should be understood as an extension of consanguinity into space. Indeed, descendants inherit the jiguan of the father, even if they are born and live thousands of kilometers away. Lin Yutang, an early twentieth-century philosopher, approached the issue from a similar perspective. He argued:

From the love of the family there grew a love for the clan, and from the love for the clan there developed an attachment for the land where one was born. Thus a sentiment arose which may be called "provincialism", in Chinese called t'unghsiang kuannien [tongxiang guannian], or "the idea of being from the same native place". . . . Fundamentally, they spring from the family psychology and do not depart from the family pattern. It is the family mind enlarged so as to make some measure of civic cooperation possible. (Lin 1998, 198) ${ }^{7}$

The reasons why the Han consider their native place such an important part of their identity are multiple. Granet ([1929] 1988, 22-23) has emphasized the strength of the tie between the people and the land already in ancient China. Like family ties, the ties between a lineage and its ancestral land were very strong and charged with obligations (R. Watson 1988). Commonly owned, lineage land could not be easily sold or leased. Like Fei Xiaotong, Granet argues that this led to a formation of spatial consanguinity that had its source in the sharing of the same "life essence" by those living on the same portion of land. It was believed that this essence was absorbed by people during meals that included foods produced on the local soil (Granet [1929] 1988, 47).

Further, I believe that filial obligation, ancestral worship, and the household registration system also converged to reinforce native place bonds. In order to fulfill filial obligations, male descendants were theoretically obliged to come back to their native place to

5ia translates as "family," "household," "home," "people who share the same surname," or "surname." Gu refers to "services of offering sacrifices," "the old," "former," or "ancient." The last element, xiang, indicates a "village," "native place," or "hometown." Goodman (1995, 2, 4) also mentions other terms like sangzi ("native place"), laojia ("old home," "native place"), or yuanji ("ancestral home," "native place").

${ }^{6}$ Zuji, where $z u$ means "ancestors" and $j i$, as above, is "record" or "registry," is a term similar to jiguan.

${ }^{7}$ Territorial bonds, like kinship bonds, come into play in economic life (Fei 1980, 95). Also, Ho Ping-ti $(1966,120)$ points out that common native place, together with kinship ties, used to be the most important basis for voluntary association. 
conduct certain ceremonies in ancestral halls located on the lineage's land, even if they had moved away in the course of their lives. Some migrants sought ways to bend this inconvenient obligation and carried elements of ancestral halls with them to rebuild them in new locations. Even then, however, the concept of native place and the bonds that linked family members to it were not neglected. They remained of vital importance, even when a new ancestral hall was built in a new location.

The household registration system was another element that tied people to the land —in this case, via the disposition of certain rights and obligations. Leong $(1997,21)$ has pointed out that imperial China developed mechanisms to limit migration and the freedom of movement because an earthbound population "facilitated record keeping, the extraction of resources and manpower, and the maintenance of social order and imperial security." Migration was thus perceived as a transgression against the law and worthy of punishment; migrants were accused of avoiding payment of taxes and fulfillment of obligatory labor. Under the Ming dynasty (1368-1644), the government strictly enforced the law that required household registration in one's native place. At this time, the penal code identified "fugitive households" (taohu) and "displaced people" (liumin) as lawbreakers. From the reign of the emperor Wanli (1573-1620) onward, policy began to change, and displaced people were given resident status (ruji) and the right to own or lease land. Also the Communist regime after 1958 introduced a strict control of population mobility (especially from rural to urban areas) by the means of the hukou system (permanent household registration). Though this system was gradually relaxed after 1978, hukou transfer is still restricted, especially in regard to migration from rural to urban areas.

The "native-place-determined mindset," a projection that native place imbues people originating in one area with an "essence" that makes them bound to it and similar to each other, was very popular among my informants. A significant number of my interviewees believed that people sharing the same native place (be it a town, city, province, or broader geographical region) share a kind of primordial "quintessence." Below, I demonstrate the ways in which this "native-placedetermined mindset" is explicitly manifest in the names and stereotypes employed by the Han.

\section{Names, Stereotypes, and Topographies of Identity}

When embarking on my research, I expected that place-boundedness and the importance of native place had diminished under the contemporary influence of immense educational and professional migration in China. I imagined that the social changes of the past two decades had weakened their significance greatly, especially among the younger generations. Against my expectations, however, a clear majority of my interviewees turned to "regional cultures" (diyu wenhua) and place-related socionyms when identifying and categorizing themselves and other Hanzu. Informants used very broad classifications, like Northerners (Beifangren) and Southerners (Nanfangren), or urban and rural Han, but also more spatially limited identifiers like Shanghairen ("natives of Shanghai," "people of Shanghai"), Henanren ("natives of Henan Province"), Taiwanren, Subeiren, and so on, with the suffix ren rendering the meaning of "native of" or, more 
generally, a "person" or "people." The "native-place-determined mindset" was often a topic of our conversations, and interviewees took great pleasure in explaining it to me. They provided numerous examples of names and nicknames for different native-place categories (including those they self-identified with), listing stereotypical characteristics and describing their relations with other categories. Although I tried to point out non-place-related categories (e.g., Tangren - "people of the Tang dynasty," a designation apparently popular in the South and abroad), these efforts elicited little response from my informants.

Most of the socionyms collected refer to locality-bound categories associated with provinces, cities, autonomous regions, and geographic regions. Further, these names indicate clearly perceived (as judged by the frequency with which they were mentioned) "pairs of oppositions": Northerners vs. Southerners, rural vs. urban Han, locals vs. outsiders/migrants. Also the category of Mainlanders (Han living in mainland China), as opposed to Taiwanese and Hongkongese, was mentioned by a number of interviewees. For an overview of identity categories signaled by names and a succinct sample of concrete socionyms, please refer to Figure 1.

The actual meaning of socionyms was quite diverse and included references to cultural discourse, history, economy, wealth and attitudes towards money, occupation, topography, character traits, physical build, language, and migration. Figure 2 offers a more careful examination of the meaning of names, as well as examples of the socionyms that illustrate them.

My interviewees also introduced the "characteristics" of the categories they identified through socionyms. During our conversations, this stereotyping occurred without any great deliberation or hesitation. Gauging from the ease with which my informants suggested these characterizations in our interviews, it is apparent that stereotyping, like naming, constitutes a familiar element of everyday social interactions. The "characteristics" or stereotypic associations I collected during the interviews comprise an enormous body of data, one that would be impossible to analyze here. I thus focus in this paper on identifying topics that surfaced repeatedly in a great number of stereotypes and socionyms, thereby signaling the aspects that are significant for differentiation between these identity categories and for the processes of boundary-making between them. Figure 3 displays topics that the stereotypes referred to most often and some examples of concrete stereotypes quoted directly from the interviews.

A significant number of interviewees shared the idea that "regional cultures" (diyu wenhua), typically imagined as geographically limited portions of the Han population, share a set of historically and ecologically determined characteristics. These characteristics in a sense predestine people within specific "regional cultures" for certain careers and occupations. For instance, Beijingren were believed to be destined to find employment as officials and bureaucrats, Shanghairen and Guangdongren as businesspeople, Anhuiren as household helpers, and Sichuanren as small-scale traders. Another theme extensively utilized by interviewees to differentiate between local identity categories was "culture" (wenhua), especially notions of "cultural level" (wenhua shuiping) and "cultural quality" (wenhua suzhi). While the former often refers to one's level of schooling, the latter is much more complex. The interviewees' understanding of "cultural quality" included the meaning of 
Figure 1. A sample of identity categories signaled by the socionyms.

Identity categories signaled by socionyms Selected examples of concrete socionyms

Province-bound

City-bound

Northerners vs. Southerners

Rural migrants vs. urban Han

Locals vs. outsiders/migrants

Mainlanders vs. Taiwanese and Hongkongese
Hubeilao ("Hubei fellow")

Luren ("native of Lu kingdom"; referring to Shandong Province today)

Xinjiangren ("native of Xinjiang")

Ala ("we" in Shanghai dialect; also indicates linguistic identification with the Shanghai dialect)

Beijingren ("native of Beijing")

Kuazi ("clumsy fellows"; referring to the Han from the North)

Beilao ("fellows from the North")

Nan manzi ("southern barbarians")

Xiao shimin ("petty townsfolk"; refers to natives of Shanghai)

Shamao ("silly billy"; used by natives of Beijing towards rural migrants)

Guazi ("dummies"; used by natives of Xi'an towards rural migrants)

Xiangxiaren ("provincialists," "rustics")

Bendiren ("local person," "native person"; used by a native of Shanghai)

Waidiren (generally "non-locals," "outsiders"; used by natives of Shanghai)

Lata ("from here"; used by an interviewee from Subei $^{8}$ )

Zhongguo de Jipusairen (lit. "Chinese Gypsies”; referring to Henanren)

Biaoshu ("maternal uncles"; indicating a person from a different descent group; used by an informant from Hong Kong; refers to Mainlanders)

Daluren ("Mainlanders")

Daomin ("islanders"; referring to Taiwanese)

Biesan ("wretched tramps and thieves"; referring to Hongkongese)

culture in the Confucian sense, ${ }^{9}$ along with topical issues pertaining to economic success and modernity (xianjin). The closest identification to culture in the sense of rituals, courtesy, good manners, etiquette, and education was ascribed to natives of Beijing by both Beijingren themselves and by others. However, while Beijingren tended to brag about it, others remarked that it made Beijingren lazy and arrogant, conservative big-talkers but "small doers." Han from the South, a collective category

${ }^{8}$ On how Subei was constructed, see Honig (1996).

${ }^{9}$ On the historical notions of wenhua see Bauer (1980), Thierry (1989), Watson and Rawski (1988), and Fairbank (1968). 
Figure 2. Main thematic fields as indicated by collected socionyms.

Thematic fields referred

to by socionyms

Culture

Historical connotations

Attitudes towards money

Work, occupation

Character traits

Body build

Language

Migration
Selected examples of concrete socionyms

Manzi ("southern barbarians")

Dalaocu ("uncouth fellows"; referring to the Han from the Northeast)

Shuren ("natives of Shu kingdom"; referring to Sichuanren)

Xiao qigui ("misers"; referring to Shanghairen)

Jiu mao jiu ("ninety-nine cents"; referring to Shanxiren and indicating "parsimonious")

Yunnan daduxiao ("drug smugglers from Yunnan")

Wenzhou xiao laoban ("little bosses from Wenzhou")

La meizi ("spicy little sisters"; refers to young Sichuan women and to their supposedly hot temper, as well as to hot Sichuan cuisine)

Jiutouniao ("nine-head birds"; referring to Hubeiren as reportedly shrewd and cunning)

Huo Lei Fengi ${ }^{10}$ ("living Lei Feng"; referring to the Han from the Northeast)

Xiao Sichuan (lit. "little Sichuan")

Shandong dahan ("burly fellows from Shandong")

Shanghai yazi ("Shanghai ducks"; refers to Shanghai dialect, which reportedly sounds like the quacking of a duck)

Bazuizi ("bigmouth"; refers to Beijingren)

$B a$ Min ("eight Min"; refers to Min languages speakers)

Kejia (lit. "guests," "guest families") ${ }^{11}$

Xilairen ("people from China’s West")

including natives of Shanghai, Taiwanese, and natives of Fujian, Guangdong, and Zhejiang Provinces, were rarely associated with the same notion of culture as Beijingren. Instead, my research participants described Han from the South as having "respect for tradition" (chuantong), and as maintaining lineage-oriented family organization and the practices of ancestral worship. Somewhat paradoxically, these very Southerners were simultaneously associated with development, advancement, flexibility, and modernity-and to a much greater and a more explicit degree than Han from the North, including "natives of Beijing."

The rapid development of commerce, industry, and the service sector in southeast China, which effected a rapid increase of wealth, particularly in urban areas, appears

\footnotetext{
${ }^{10}$ Lei Feng (1940-62) was reportedly a selfless young soldier who was devoted to helping people, working for the fatherland, and studying the works of Mao. After his death in an accident, Lei Feng was transformed through a nationwide campaign into a model hero. He was portrayed as being hard-working, helpful, cheerful, obedient, and wholeheartedly devoted to communism.

${ }^{11}$ On Kejia, see Constable (1996).
} 
Figure 3. Main narratives as indicated by collected stereotypes and examples of stereotypes.

\begin{tabular}{lc}
\hline Main topics & Selected examples of stereotypes \\
\hline Work, money, economy & Zhejiangren ("natives of Zhejiang") have \\
brains for business; Hubeiren ("natives of & Hubei”) are cunning; Henanren are lazy; \\
Shanxiren are the "traders of the North"; & Beijingren prefer to become officials \\
rather than businessmen; Xinjiangren are & oil-field workers; Wenzhouren are daring; \\
many Kejia work abroad
\end{tabular}

Culture, cultural level (wenhua shuiping), Sichuanren are unsophisticated; Dongbeiren cultural quality (wenhua suzhi)

Openness, flexibility, modernity are wild and uncivilized; Beijingren possess high "cultural quality"; Hongkongese have no culture; Subeiren have a low "cultural level"; urban Han are quite civilized

Shanghairen like changes; Tianjinren are conservative; Guangdongren are flexible; Hongkongese are open in thinking and well-informed; Hakka are feudal; Mainlanders are badly educated and conservative

Tradition, respect for tradition

Family lineages are very powerful in Fujian; Taiwanese care for tradition; Hakka follow etiquette and show filial obedience

Interpersonal relations

Dongbeiren ("people from the Northeast") are very loyal and ready to help friends; Hongkongese are cold and unconcerned; Sichuanren are warm-hearted and honest

Relationships with other identity categories

Shandongren resemble Dongbeiren; Beijingren do not like Shanghairen; Zhejiangren resemble Guangdongren

Languages, dialects

Beijingren speak standard Chinese; Guangdong speech is a separate language; Fujianren speak Minnan languages; Tianjinren speak with a strong dialect; Nanjing men talk gently, "like silk"

Culinary variety

Sichuanren love eating spicy foods; Guangdongren are gourmands; Tianjinren like crunchy foods; Hunanren like eating spicy foods

Physical appearance

Shandongren are tall and robust; Northerners are stockier than Southerners

Character traits

Hangzhouren are romantic; Guangdongren are deceptive; Shanghairen are shrewd; Taiwanese are good-natured; Henanren are dishonest and evil; Yunnanren seek a carefree life; Chengduren are at ease; people from the Central Plains are honest and simple 
to have resulted in wariness and disgust toward agrarian occupations, sentiments that most of my interviewees most prominently associated with the Han who originated in the northern agricultural provinces of Hebei, Shanxi, and Henan. Rural Han from the North were labeled as "uneducated" (wenhua shuiping di), "backward" (luohou), and "feudal" (fengjian). By contrast, occupations in the business sector have come to receive more social respect. Though despised under Mao, the social regard for these jobs changed diametrically with Deng Xiaoping's economic reforms in the 1980s. The increasing significance of individual wealth and economic success is reflected in the clear categorical division between those who are "good with business" but "lack culture" and are "detached in personal contacts" (used in reference to natives of Fujian, Guangdong, Shanghai, Taiwan, and Hong Kong; generally, Southerners); and those who "lack the economic spirit" and are "not hard-working" but nonetheless remain "immersed in traditional culture" and "warm-hearted" (natives of Hebei, Beijing, and the Northeast; generally Northerners). This opposition between the North (Beifang) and the South (Nanfang) constitutes the central axis of stereotypic comparisons, despite late imperial and twentieth-century efforts to overcome it with one "Han" ethnonym and the notion of a united minzu. ${ }^{12}$

Somewhat surprisingly, the discourse on linguistic diversity was reflected in relatively few stereotypes, despite the great linguistic diversity of the Hanzu. This result may relate to the fact that all of my interviewees were fluent in the national standard (Putonghua $)^{13}$ and were in the course of receiving (or had already received) a tertiary education in it. It may also suggest that for the younger, educated generation of migrating Han, linguistic differences could be of lesser importance than earlier.

Although limited space does not allow me to comment on all the narratives, the data I have collected offer compelling insights into categorization and identification processes fragmenting the Han on the non-minzu scale of interaction. Stereotypes and socionyms manifest the aspects that the research participants perceived as differentiable between the identity categories with which they identified and with which they identified others. While stereotypes reinforce and naturalize the boundaries between the categories, they also provide individuals with subjectively meaningful explanations of the events and processes that affect them. Difficulties on the job market, at work, in finding a spouse, or in taking exams can all be "explained" through the language of stereotypes. Native place was believed to play a significant role in all of these issues. Han from Henan Province would ascribe their difficulties on the job market to work discrimination against Henanren. The same would be claimed by Subeiren. At the same time, others would identify themselves as excellent businesspeople solely on account of their origin in southern China. Still others would claim cultural superiority just because they were "natives of Beijing." Through this complicated game of difference and discrimination, the fragmented Hanzu attempt to position themselves and others on the intra-Han hierarchies of power that have very practical effects on everyday life.

\footnotetext{
${ }^{12}$ For a historical perspective on the North-South boundary see Elliott (2012).

${ }^{13}$ Putonghua (lit. "common speech") is the national language standard referred to in the West as "Mandarin Chinese."
} 


\section{Terminological Deliberations}

How to grasp in analytical terms the multitude of local identity categories, which, on the one hand, remain in competition with one another and, on the other hand, exist alongside a common identity as Hanzu, served as one of the central questions of my study. There exist many different analytical approaches to this issue. A number of researchers discuss Shanghainese, Sichuanese, Hakka, Hokkien, Cantonese, or Chaozhou in terms of "sub-ethnic" distinctions, divisions, or groups (J. H. Cole 1996, 161; Moser 1985; Rowe 1984, 247; J. Watson 1988, 133). Countering this approach, Crossley $(1990,15)$ and Brown $(2004,7)$ argue that conceiving of these categories in sub-ethnic terms is unwarranted and misleading, as they are ethnic in their own right. Likewise, Hakka, Hokkien, and Swatow, according to Gladney (1998, 70), and Cantonese, Hokkien, or Boat People, according to Blake (1981) and Skinner (2001), each have exclusive ethnic identities. ${ }^{14}$ Lipman (1996, 97-98) succinctly summarizes these approaches, arguing that "conventional definitions of ethnicity cannot contain the variables - dialect, native place, economic status, immigration history, among others - that divide and unite groups of people in China."

As I analyzed my research data, I at times struggled to meaningfully apply this ethnic approach. I wondered if there were other ways by which I could analytically reconcile the variety of non-minzu identity categories like Subeiren, Southerners, locals, urbanites, or Hakka, with the Han minzu identification. Are they all ethnic? In what follows, I offer a possible solution. In the first section, I argue that it is necessary to first put aside the reifying term "ethnic group" and turn to Chinese-language terms in order to understand the relationship that binds local identities to one another and to the Han minzu. In the second section, I return to the question of ethnicity and discuss whether the categories of identity I refer to in this paper and the relationships that bind them can be grasped with this concept.

\section{Minzu, Ren, Min, and Jia}

In this paper I have so far refrained from employing the term "ethnic group" in my discussion of the various identity categories I identified in my research, such as Northerners, Hongkongese, Hakka, Beijingren, Henanren, and many more. At this early stage of my analysis, the term "ethnic group" would reify and conceal my data in troubling ways. In this, I agree with Tapper $(1988,31)$, who argues that the term "ethnic group" tends to add superfluous terminology to an already complex field: "Ethnic group, a term brought in from western sociological discourse, is a poor translation of indigenous categories ... and hinders the analysis of their subtleties and ambiguities." Thus, following Tapper's idea, I turned to my research material and primary literature in search of indigenous terms for the identity categories I encountered and found four, namely: minzu 15 ("nationality," "ethnic group," "nation”), ren (“person," e.g., Beijingren), min

\footnotetext{
${ }^{14}$ In Chinese publications, these terms also abound. Among them are "Han communities" (汉人社 区; Hanren shequ), “sub-groups of Hanzu” (汉族次生集团; Hanzu cisheng jituan, or 汉族亚群体; Hanzu yaqunti), “lineage groups" (族群; zuqun), “human groups” (人群; renqun), or simply "groups" (群体; qunti). They are also referred to as "branches within the minzu" (民系; minxi).

${ }^{15} \mathrm{Minzu}$ is actually not an indigenous category of identity sensu stricto but, rather, it was imported from Japan at the turn of the twentieth century.
} 
(“person," e.g., Danmin, lit. "Boat Person"), and jia ("person," “family," e.g., Kejia, lit. "Guest Family"). In the section that follows, I focus briefly on the usage and meaning of these four terms.

Following the immense Minzu Classification Project launched by the Communist government in the 1950s to identify and classify the multiethnic population of the new state, fifty-six minzu were identified. Although it is estimated that there are more than 200 ethnic groups in the PRC, only fifty-six (some of them combinations of several ethnic groups) were officially recognized by the state and given the official denomination as minzu (nationality). ${ }^{16}$ Hence, it has been argued that minzu are stiff categories, conceived of and imposed by the state on a fluid ethnic reality. As Harrell $(1989,181)$ points out, "what ultimately makes a group a minzu is that the government, more precisely the Minzu Commission . . . , says it is one." While this is true in regard to ethnic groups with limited access to power, as a powerful majority, the Han minzu seems to require a different conceptual approach. The question becomes, what actors have narrated the modern Han minzu into being? It is important to emphasize Wicker's (1997, 1) argument, that

formations which appear as ethnic groups, as cultures, or as nations . . . should be interpreted as the products of history, therefore as resulting from concrete acts that are motivated by people's interests. Such formations are constructions naturalized by social actors in the interest of their own social standing.

Han-ness is not a modern invention, even though the Han ethnonym was at first highly unstable. As Elliott (2012) demonstrates, only from the fifteenth century onward "Han" began to stabilize and began to refer to both northern and southern Chinese (Zhongguoren), a scope it roughly has today. In a complex interplay of local and empire-wide processes, those who identified with Han-ness constructed and maintained boundaries between themselves and "uncivilized others" by cultivating specific rites, using family names, constructing genealogies, and more.

Alongside transformations in the political arena, at the turn of the nineteenth century, political and intellectual Han elites redefined quite diametrically the role and meaning of "Han," in an effort to reimagine it as national community with a common ancestor and a linear national history. This national imagery was later also adopted by the Communists, who additionally glorified "the Han" as a world-leading revolutionary nation. It should thus be emphasized that the Han minzu is not a category produced by distant state institutions. Rather, it is a collective category that has been reinvented by those who have identified with Han-ness themselves in pursuit of specific interests, and has emerged in a complex interplay of local and state-wide processes. Therefore I argue that minzu, particularly in the context of the Han, is not necessarily stiff or arbitrarily imposed, ${ }^{17}$ although the Han-dominated state certainly reinforces it for its own sake.

When it comes to local identity categories, three popular Chinese-language terms are employed: ren, min, and jia. All of them can be translated as "people" or "person,"

\footnotetext{
${ }^{16}$ For a detailed analysis of this process see Mullaney (2011).

${ }^{17}$ Yet, we should not forget that the label was imposed onto some local groups and was denied to others during the process of minzu recognition. For examples see Fei (1980).
} 
but each also has its distinct connotations. Most of the identity categories I collected in my research were referred to with the term ren, which translates as a "person" or a "native of," the locality aspect being well-pronounced. While ren is indisputably the most common designation, some of the local identity categories are referred to with the term jia, for instance in the socionym Kejia ("guests," "guest families"). The term jia can be translated either as "family," "household," "members of one family name group," or as a "family engaged in a certain occupation," which implies a stronger kinship basis. The third term, min, absent in my research material but present in literature in the terms Danmin (Boat Person or Boat People) (E. Anderson 1972) or Duomin (Fallen Person or Fallen People) (Cole 1982), translates as "a person of a certain occupation" or a "civilian." It emphasizes occupational identity. Now classified as Hanzu, Duomin and Danmin once belonged to the category of jianmin ("demeaned people," "déclassé”), who, unlike “commoners" (liangmin, also "decent people”), engaged in occupations of low social status that were often hereditary (see Eberhard 1962).

Each of these three terms, ren, jia, and min, has different connotations. Ren refers to identity bound to locality; jia is kinship-related, connoting a household or a family; and min refers broadly to occupation and civilian status. These terms are critical in understanding the historical background of local identity-categories in China and the paradigms on which they were constructed. The terms suggest that locality-bonds, occupational specialization, kin-bonds, and family-names used to be important identity coordinates. As my research evidences, these terms have also moved into the twenty-first century, where they continue to be practiced. I argue that the understanding of their connotations and their intertwinement is crucial to the discussion of ethnicity. That these categories connote multiple membership and nonexclusivity is unavoidable and preprogrammed; hence, it is perfectly compatible to be simultaneously, for example, a "native of Fujian," Kejia, and Hanzu.

That most, though not all, of my interviewees did not express objections to the fact that these various place-, occupation-, and kinship-based identity categories are all lumped together under the category of Han minzu suggests that Han-making projects have been largely successful. In my experience, only very few people classified as Hanzu would insist on being divided into distinct Hakka minzu, Beijing minzu, Cantonese minzu, and so on. ${ }^{18}$ I doubt that any of my informants would voluntarily give up Hanzu membership to become exclusively Cantonese, exclusively Hakka, or exclusively Pekinese, despite the importance they may attach to these identity labels. The Han, as "the core of the nation," have been ascribed extreme political and social relevance, as well as historical and cultural greatness. Hence, membership in the category offers access to potent symbolic resources that very few seem willing to give up. ${ }^{19}$ This was clearly evidenced during the interviews, where at any reference to non-Han minzu,

\footnotetext{
${ }^{18}$ Compare this with Carrico's (2012) study in Guangdong, which finds people actually calling for the independence of Guangdong from the North. Yet, I understand this call to be aimed at the revision of power relationships with Northerners rather than at independence from Han-ness.

${ }^{19}$ But see for instance Halskov Hansen $(2005,40)$, who reports of Han cadres in Sipsong Panna registering their children as "minorities." Also, children of mixed couples (Han and non-Han) have the right to choose between the minz $u$ affiliations of their parents; apparently, they often decide to identify as a "minority," as this status connotes certain advantages (e.g., permission to legally have more children, priority access to positions in local governments, and extra points for the entry exams to universities).
} 
the majority of my informants promptly abandoned their discussion of intra-Han differentiation, and turned instead to reiterating "the Han" as a powerful national majority and the big brother of other "nationalities."

\section{Conclusions: IS THIS ETHNICITY?}

Although I agree with Tapper (1988) that the use of local categories of identity is crucial in the early stages of analysis, I believe it is equally important to go beyond the "locality" and specificity of the Chinese context at the advanced stage of analysis and consider a more universal query, namely: Are minzu, ren, min, and jia ethnic? Are the relationships they form relationships of ethnicity?

Ethnicity has been most often referred to as an ongoing process of identification between at least two collective actors: "us" and "them." As Wallman $(1979,3)$ argues, "Ethnicity is the process by which 'their' difference is used to enhance the sense of 'us' for purposes of organization or identification"; hence it can only happen at the boundary of "us," in contact or by contrast with "them" (see also Jenkins 1997, 53). Whereas the interactive relationship between "us" and "them" is certainly crucial to ethnicity, Barth (1994, 19-20), Harrell (1996), and Gladney (1998) urge us to see the state as a third component in processes of ethnicity. Harrell $(1996,274)$ emphasizes that "ethnic consciousness and identity arise in a three-way interplay between a group that considers itself distinctive, neighboring groups from which the group distinguishes itself and the state, which establishes categories . . . and distributes benefits." Likewise, Cole and Wolf ([1974] 1999) demonstrate that local processes of boundary making can only be understood when linked to the work of the states and to developments on the macro-scale with which they remain in a relationship of mutual dependence.

Benedict Anderson $(1983,15)$ points out that "all communities are imagined"; only the ways in which they are imagined differ. Hence, whereas processes of categorization and identification are universal, they are not always ethnic (see Brubaker 2004; Martiniello 1995). What is it, then, that makes ethnicity different from social categorization? Contrary to social organization forms, ethnicity is not always voluntary. Nor is it necessarily instrumental. Moreover, ethnicity, especially in times of mobilization, tends to employ essentialist discourses of shared culture, shared blood, common origin, and common history (Eriksen 2002; Jenkins 1997; Roosens 1989). The belief in common descent, history, and shared culture, as well as the sense of shared destiny, are essential to ethnicity. It is a notion that builds on continuity in time, both imagined and actual. Reliance on ideologies of common ancestry, history, and culture, all of which project the present onto the past, constitutes the core strategy of ethnic boundary-making and maintenance (Barth [1969] 1996). As Harrell (2001) argues, ethnicity can manifest in various ways but will mostly combine these three aspects: culture (the so-called "ethnic markers" that make "us" similar to one another but different from "them"), kinship (imagined and actual), and history (invented continuity within "us" and the history of conflict with "them"). When not in situations of confrontation and conflict, ethnicity seems to be quite flexible; it does not need to be framed in essentialist terms and can be practiced as a non-total, non-exclusive, instrumental, and situational paradigm. This flexibility is only restricted by the relational quality of ethnicity, which necessitates the recognition of the switches and negotiations performed 
by not only other "us" but also "them." Hence, until the moment of confrontation, beyond which switches in ethnicity are made more difficult by exclusivist and essentialist narratives, distinguishing between social and ethnic identities is a difficult task. Still, I believe it makes sense to draw boundaries around the concept of ethnicity. If we label every form of categorization process "ethnic," it will quickly lose its meaning and relevance. To keep this concept useful, social, ethnic, and national categorization processes should be kept analytically distinct to the extent that the fluid, changing reality permits. This will allow for an understanding of each categorization process in its own right, a thorough recognition of its specificities, and a discussion of its effects. To meaningfully apply the concept of ethnicity to my research material, I explore in the remainder of this paper the idea of "degree of ethnicity" and "transitory ethnicity," suggesting that whereas the Han identity is more ethnic, the ren, min, and jia identities appear to a lesser degree ethnic and more transitory in their ethnicity. I explain my claim below.

\section{Exclusivity}

The first difference between the minzu category and the ren, min, and jia categories is connected to the concept of exclusivity. As I have demonstrated above, the ren, jia, and min categories connote multiple membership. Indeed, due to their different connotations, multiple membership in these categories is virtually unavoidable. As they are conceptualized and used, these categories are nonexclusive. Many of my interviewees emphasized having multiple attachments to ren and jia categories. However, exclusivity is an important element of ethnic discourses, if not of ethnic realities. Particularly in times of mobilization, loyalty to one ethnic category is expected. Hence, I argue that in contemporary China, ren, jia, and min identities are too overlapping, mutually inclusive, and intertwined to discursively connote ethnicity.

While earlier the relationship between local identities and Han-ness has been different, from the nineteenth century onward, the mobilizing power of ren, min, and jia identities have been challenged by an increasingly powerful notion of Han-ness (compare Giersch 2012). Also in the twentieth century, central governments invested great efforts in narrating local identities as secondary to Han-ness. Likely because of this, in a stark contrast to ren, min, and jia attachments, the overwhelming majority of my interviewees perceived the boundaries between the Han minzu and other minzu as discursively obvious, clear-cut, and impassable. ${ }^{20}$

\section{Flexibility}

The second point refers to flexibility, a notion directly related to exclusivity. My research material demonstrates that the ren, min, and jia identities are much easier to access and easier to switch between than minzu. Also, because they are not state-regulated,

\footnotetext{
${ }^{20}$ The fact that the interviews were carried out in Han-dominated cities might have had a significant influence on this structure of responses. In multiethnic areas, other paradigms could potentially be more important than minzu for identification. In earlier research in southwest Sichuan, I observed that minzu identities coexisted with ethnic identities from the pre-Communist period. Though classified today as one minzu, some ethnic groups would not intermarry (e.g., Prmi and Bo, which were both classified as "Tibetans"). Simultaneously, others who were classified as two different minzu would (e.g., Prmi and Na, classified as "Mongol").
} 
access to and shifts between them are more widespread than between minzu. Ethnicity, however, because it involves the third actor-the state, and a recognition by an "other"-is not always flexible and voluntary. In relational terms, ren and jia identities are today much more flexible and individual-dependent than Han-ness. For instance, although most of the interviewees emphasized that native place was extremely important to them, what they actually defined as "native place" was defined in accordance with their current situation. Native place was thus variously understood as father's place of origin or birth, mother's place of origin or birth, current place of living, hukou location, birthplace, place where one grew up, and more. Additionally, it became clear in our interviews that Han individuals maintained and shifted between multiple ren and jia attachments. My informants exhibited a number of native place or ren identities that were non-exclusive and could be flexibly switched. If a person had lived for some years in Beijing, she might start referring to herself as "native of Beijing" when confronted with more recent migrants. On the other hand, when confronted with Han from her birthplace, she would refer to herself using her birthplace identity. It also happened that interviewees ascribed to themselves native-place identities with which they wished to be identified, for instance as "natives of Shanghai," instead of clinging to labels that were lower on the social hierarchies. Thus, every interviewee had a number of native-place identities that were nonexclusive and could be flexibly switched. Although Han-ness is sometimes instrumentalized too, a similar degree of flexibility is hard to imagine on the scale of minzu categorization. Unlike the ren, min, and jia categories, minzu are imagined, and to a great extent also lived by Han individuals as stable, given, and mutually exclusive categories of identity. This representation of minzu identities is obviously enforced by a powerful state apparatus, which contributes significantly to the prevalence of such imagery.

\section{Shifting Scales and the State}

The third point of my argument involves scales of interaction, and the role of state policies in determining the meaning of these scales. As I have observed in non-Han dominated areas, particularly in the region of Xinjiang, divisions into rural and urban Han, into natives of Shanghai, Guangdong, or the Northeast, or into Northerners and Southerners are quickly downgraded when Han are exposed to a minzu "other." The Han, fragmented otherwise by numerous boundaries of native place or occupation, tend to promptly disregard this fragmentation and identify with their Han-ness when exposed to other minzu. When a Sichuanren comes across a Uyghur in Xinjiang, he or she tends to not emphasize his or her Sichuan native place identity. Rather, the Sichuanren would here typically emphasize his or her Han-ness. This is because the Han minzu and the Uyghur minzu exist in a mutually reifying relationship that has a clear ethnic quality, as discussed above. While important in other situations, the fragmented native place, occupation, and kinship identities of the Han are irrelevant to this relationship. These identities relate to and exist at different scales of interaction. With regard to the Han, I argue that this scale of minzu-to-minzu interactions is more ethnic than the scale of ren, min, and jia identities. ${ }^{21}$ Ethnic identity, in order to fulfill its purpose, must also be performed

\footnotetext{
${ }^{21}$ With regard to other minzu, including those that became combinations of a number of ethnic groups, the situation might be diametrically different.
} 
in relation to some "others." The Han minzu has very clear "others" in the form of the fifty-five so-called "minorities." With regard to Sichuanren, Henanren, Wuhanren, Zhejiangren, or Wenzhouren, these "others" are very diffuse. My impression is that these categories do not have very clear "others"; rather, they coexist in a relational system of identification against some and with others. For instance, numerous interviewees said that Shandongren are like Dongbeiren, or that Zhejiangren are like Shanghairen. According to selected criteria, however, "alliances" and "others" shift. For instance, according to the criteria of language, categories regarded as similar to "us" will not be the same as when the criteria of "cultural quality" or "progress" is used for categorization. Hence, I argue that the aim of differentiations and categorizations on the scale of ren, min, and jia identities is not about drawing excluding boundaries between a specific "us" in relation to a specific "them." Rather, it involves locating and positioning oneself in a relational system formed by multiple ren, min, and jia identities that fluctuate in relation to multiple reference points.

Accordingly I argue that the ren, min, and jia categories do not possess a similar degree of "density" and exclusivity like minzu. To compare, would the boundaries between Uyghur and Han become less salient if they met outside of China? Would the international scale render Han-ness and Uyghur-ness unimportant? From my observations, it would not. The national Chinese identity does not have the power to make ethnic boundaries between Han and Uyghur irrelevant. The same cannot be said in a similar degree about the relationship between ren, min, or jia identities. Although differences in language or native place may be registered, their influence on social practice will be relatively less significant. In these differentiated relationships, the role of state as the third actor in the processes of ethnicity becomes again explicitly manifest. Because ren, jia, and min identities are not promoted as collective identities by the state, they are not capable of achieving a degree of "density" similar to the institutionalized minzu. In the PRC, where the government presence is so pervasive, the state component in processes of ethnicity should be given even more weight than elsewhere.

I believe the notions of relationality, degree, and scales are of utmost importance to the discussions of ethnicity. In the three points above, I argue that while the Han minzu is related to other minzu in China by a relationship of ethnicity, ren, min, and jia categories are less ethnic and more social in relation to one another and to the minzu. They overlap, they do not claim exclusivity, and they lack the mobilizing energy of the minzu. The importance of these categories fades as scales of interaction change in instances of confrontation with other minzu because they lack the institutional backing of the state. However, I believe that in regions where a minzu "other" is not present in daily interactions, ren, min, and jia attachments become "ethnic," albeit in a transitory way. Likewise, an urban-rural, or migrants-locals boundary might become ethnic in Han-dominated environments like eastern Chinese cities. In such settings, these identities are viewed as more meaningful and emotional ${ }^{22}$ than Han-ness; they assume the cloak of primordiality and also have certain organizational functions. From my

\footnotetext{
${ }^{22}$ Fifty-one out of ninety-one research participants declared that they felt emotionally more attached to the ren and jia categories than to minzu. However, these results must be contextualized by where I conducted my interviews: in the Han-dominated cities of Beijing and Shanghai, where ethnic "others" are often relatively difficult to locate.
} 
observations, however, whenever Han-ness is perceived to be threatened, the ethnicity of these categories diminishes. The success of Han-making projects is manifest in the fact that ren, min, and jia categories have become to a significant degree naturalized as "Han." As my informants demonstrated, these categories are currently conceived of as parts of the same symbolic entity, the Han minzu. Hence, in contemporary China, being Hanzu is perfectly compatible with having additional ren, min, and jia identities. Each of these identities has a certain function and is relationally and situationally meaningful. While Han-ness helps the Hanzu position themselves in relation to other minzu, non-minzu identities help them orientate and position themselves in relation to other Hanzu.

\section{Acknowledgments}

I would like to thank the Polish and Chinese Ministries of Education and the Swiss Federal Commission for Scholarships for Foreign Students, which, through their generous support, made this research possible. I also would like to thank Leszek Sobkowiak and Mieke Matthyssen for hosting me during the fieldwork and Hans-Rudolf Wicker, Martin Sökefeld, Judith Hangartner, Sue Thüler, Steve Harrell, Tom Mullaney, the three anonymous reviewers, and Jeffrey Wasserstrom for their helpful and encouraging comments.

\section{List of References}

Anderson, Benedict. 1983. Imagined Communities: Reflections on the Origin and Spread of Nationalism. London: Verso.

Anderson, Eugene N. 1972. Essays on South China's Boat People. Asian Folklore and Social Life Monographs 19. Taipei: Orient Cultural Service.

Barth, Fredrik. 1994. "Enduring and Emerging Issues in the Analysis of Ethnicity." In The Anthropology of Ethnicity: Beyond 'Ethnic Groups and Boundaries,' eds. Hans Vermeulen and Cora Govers, 11-32. Amsterdam: Het Spinhuis.

—_. [1969] 1996. "Ethnic Groups and Boundaries." In Theories of Ethnicity: A Classical Reader, ed. Werner Sollors, 294-324. London: Macmillan Press.

Bauer, Wolfgang, ed. 1980. China und die Fremden [China and its strangers]. Munich:

C. H. Beck'sche Verlagsbuchhandlung.

Blake, C. Fred. 1981. Ethnic Groups and Social Change in a Chinese Market Town. Asian Studies at Hawaii 27. Honolulu: University of Hawai'i Press.

Bourdieu, Pierre. 1991. Language and Symbolic Power. Cambridge, Mass.: Harvard University Press.

Brown, Melissa J. 2004. Is Taiwan Chinese? The Impact of Culture, Power, and Migration on Changing Identities. Berkeley: University of California Press.

Brubaker, Rogers. 2004. Ethnicity without Groups. Cambridge, Mass.: Harvard University Press.

Carrico, Kevin. 2012. "Recentering China: The Cantonese in and beyond the Han.” In Critical Han Studies: The History, Representation, and Identity of China's Majority, eds. Thomas S. Mullaney et al., 23-44. Berkeley: Global, Area, and International Archive and University of California Press. 
Chow, KaI-wing. 2001. "Narrating Nation, Race, and National Culture: Imagining the Hanzu Identity in Modern China." In Constructing Nationhood in Modern East Asia, eds. Kai-wing Chow, Kevin M. Doak, and Poshek Fu, 47-83. Ann Arbor: University of Michigan Press.

Cole, James H. 1982. "Social Discrimination in Traditional China: The To-min of Shaohsing." Journal of the Economic and Social History of the Orient 25(1):100-11. - 1996. "Competition and Cooperation in Late Imperial China as Reflected in Native Place and Ethnicity.” In Remapping China: Fissures in Historical Terrain, eds. Gail Hershatter, Emily Honig, Jonathan N. Lipman, and Randall Stross, 156-63. Stanford, Calif.: Stanford University Press.

Cole, John W., and Eric R. Wolf. [1974] 1999. The Hidden Frontier: Ecology and Ethnicity in an Alpine Valley. Berkeley: University of California Press.

Constable, Nicole. 1996. "Introduction: What Does It Mean to Be Hakka?" In Guest People: Hakka Identity in China and Abroad, ed. Nicole Constable, 3-35. Seattle: University of Washington Press.

Crossley, Pamela Kyle. 1990. "Thinking about Ethnicity in Early Modern China.” Late Imperial China 11(1):1-34.

Duara, Prasenjit. 1995. Rescuing History from the Nation: Questioning Narratives of Modern China. Chicago: University of Chicago Press.

Eberhard, Wolfram. 1962. Social Mobility in Traditional China. Leiden: E. J. Brill.

Elliott, Mark. 2012. "Hushuo: The Northern Other and the Naming of the Han Chinese." In Critical Han Studies: The History, Representation, and Identity of China's Majority, eds. Thomas S. Mullaney et al., 173-90. Berkeley: Global, Area, and International Archive and University of California Press.

Eriksen, Thomas Hylland. 2002. Ethnicity and Nationalism: Anthropological Perspectives. 2nd ed. London: Pluto Press.

Fairbank, John KIng. 1968. The Chinese World Order. Cambridge, Mass.: Harvard University Press.

Faure, David, and Helen F. Siu, eds. 1995. Down to Earth: The Territorial Bond in South China. Stanford, Calif.: Stanford University Press.

Fei Xiaotong [Fei Hsiao-Tung]. 1980. "Ethnic Identification in China.” Social Sciences in China 1:94-107.

—. 1992. Hsiang t’u Chung-kuo [From the soil: The foundations of Chinese society]. Berkeley: University of California Press.

Giersch, C. Patterson. 2012. "From Subjects to Han: The Rise of Han as Identity in Nineteenth-Century Southwest China." In Critical Han Studies: The History, Representation, and Identity of China's Majority, eds. Thomas S. Mullaney et al., 191209. Berkeley: Global, Area, and International Archive and University of California Press.

Gladney, Dru C. 1994. "Representing Nationality in China: Refiguring Majority/ Minority Identities.” Journal of Asian Studies 53(1):92-123.

_ 1998. Ethnic Identity in China: The Making of a Muslim Minority Nationality. Case Studies in Cultural Anthropology. Fort Worth, Tex.: Harcourt Brace College Publishers.

Goodman, Bryna. 1995. Native Place, City, and Nation: Regional Networks and Identities in Shanghai, 1853-1937. Berkeley: University of California Press.

Granet, Marcel. [1929] 1988. Die Chinesische Zivilisation: Familie, Gesellschaft, Herrschaft; von den Anfängen bis zur Kaiserzeit [The Chinese civilization: Family, 
society and power from the beginnings to the imperial period]. Frankfurt: Suhrkamp.

Halskov Hansen, Mette. 2005. Frontier People: Han Settlers in Minority Areas of China. London: Hurst and Company.

Harrell, Stevan. 1989. "Ethnicity and Kin Terms among Two Kinds of Yi." In Ethnicity and Ethnic Groups in China. Special issue, New Asia Academic Bulletin 8, eds. Chien Chiao and Nicolas Tapp, 179-97. Hong Kong: New Asia College.

_ 1996. "The Nationalities Question and the Prmi Prblem [sic]." In Negotiating Ethnicities in China and Taiwan, ed. Melissa Brown, 274-94. Berkeley: University of California.

—. 2001. Ways of Being Ethnic in Southwest China. Seattle: University of Washington Press.

Harrison, Henrietta. 2001. China. Inventing the Nation. London: Oxford University Press.

Ho PING-TI. 1966. “The Geographic Distribution of hui-kuan (Landsmannschaften) in Central and Upper Yangtze Provinces." Tsing Hua Journal of Chinese Studies 5: $120-52$.

Hoffman, Curt, and Nancy Hurst. 1990. "Gender Stereotypes: Perception or Rationalization?” Journal of Personality and Social Psychology 58(2):197-208.

Honig, Emily. 1992. Creating Chinese Ethnicity: Subei People in Shanghai, 1850-1980. New Haven, Conn.: Yale University Press.

—. 1996. "Native Place and the Making of Chinese Ethnicity." In Remapping China: Fissures in Historical Terrain, eds. Gail Hershatter, Emily Honig, Jonathan N. Lipman, and Randall Stross, 143-55. Stanford, Calif.: Stanford University Press.

Jenkins, Richard. 1997. Rethinking Ethnicity: Arguments and Explorations. London: Sage Publications.

Jost, John T., and Mahzarin R. Banaji. 1994. "The Role of Stereotyping in SystemJustification and the Production of False Consciousness." British Journal of Social Psychology 33:1-27.

Leibold, James. 2006. "Competing Narratives of Racial Unity in Republican China: From the Yellow Emperor to Peking Man.” Modern China 32(2):181-220.

_ 2012. "Searching for Han: Early Twentieth-Century Narratives of Chinese Origins and Development." In Critical Han Studies: The History, Representation, and Identity of China's Majority, eds. Thomas S. Mullaney et al., 210-33. Berkeley: Global, Area, and International Archive and University of California Press.

Leong, Sow-Theng. 1997. Migration and Ethnicity in Chinese History: Hakkas, Pengmin, and Their Neighbors. Stanford, Calif.: Stanford University Press.

Leyens, Jacques-Philippe, Vincent Yzerbyt, and Georges Schadron. 1994. Stereotypes and Social Cognition. London: Sage Publications.

Lin Yutang. 1998. My Country and My People//Wu guo yu wu min. Beijing: Foreign Language Teaching and Research Press.

Lipman, Jonathan N. 1996. "Hyphenated Chinese: Sino-Muslim Identity in Modern China." In Remapping China. Fissures in Historical Terrain, eds. Gail Hershatter, Emily Honig, Jonathan N. Lipman, and Randall Stross, 97-112. Stanford, Calif.: Stanford University Press.

Liu Xiaochun. 2003. Beijingren shenmeyang? [What are the Beijingren like?]. Beijing: Xueyuan Chubanshe.

Martiniello, Marco. 1995. L'ethnicité dans les sciences sociales contemporaines [Ethnicity in contemporary social sciences]. Paris: Presses Universitaires de France. 
Moser, Leo J. 1985. The Chinese Mosaic: The People and Provinces of China. Boulder, Colo.: Westview Press.

Mullaney, Thomas S. 2011. Coming to Terms with the Nation: Ethnic Classification in Modern China. Berkeley: University of California Press.

Naquin, Susan, and Evelyn S. Rawski. 1987. Chinese Society in the Eighteenth Century. New Haven, Conn.: Yale University Press.

Oakes, Penelope J., S. Alexander Haslam, and John C. Turner. 1994. Stereotyping and Social Reality. Oxford: Blackwell Publishers.

Oakes, Penelope J., and Katherine J. Reynolds. 1997. “Asking the Accuracy Question: Is Measurement the Answer?” In The Social Psychology of Stereotyping and Group Life, eds. Russell Spears, Penelope J. Oaks, Naomi Ellemers, and S. Alexander Haslam, 51-71. Oxford: Blackwell Publishers.

Rhoads, Edward J. M. 2000. Manchus and Han: Ethnic Relations and Political Power in Late Qing and Early Republican China, 1861-1928. Seattle: University of Washington Press.

Roosens, Eugeen E. 1989. Creating Ethnicity: The Process of Ethnogenesis. Frontiers of Anthropology 5. Newbury Park, Calif.: Sage Publications.

Rowe, William T. 1984. Hankow: Commerce and Society in a Chinese City, 1796-1889. Stanford, Calif.: Stanford University Press.

Sherif, Muzafer. 1967. Group Conflict and Co-operation: Their Social Psychology. London: Routledge and Kegan Paul.

Skinner, G. William. 2001. Marketing and Social Structure in Rural China. Ann Arbor, Mich.: Association for Asian Studies.

Spears, Russell, Penelope J. Oakes, Naomi Ellemers, and S. Alexander Haslam. 1997. "Introduction: The Social Psychology of Stereotyping and Group Life." In The Social Psychology of Stereotyping and Group Life, eds. Russell Spears, Penelope J. Oaks, Naomi Ellemers, and S. Alexander Haslam, 1-19. Oxford: Blackwell Publishers.

TAjfel, Henri. 1969. “Cognitive Aspects of Prejudice.” Journal of Social Issues 25:79-97.

—. 1981. Human Groups and Social Categories. Cambridge: Cambridge University Press.

Tajfel, Henri, M. G. Billig, R. P. Bundy, and Claude Flament. 1971. "Social Categorization and Intergroup Behaviour." European Journal of Social Psychology 1(2): 149-78.

Tapper, Richard L. 1988. "Ethnicity, Order and Meaning in the Anthropology of Iran and Afghanistan." In Colloques internationaux 'Le fait ethnique en Iran et en Afghanistan' [International symposium 'Ethnic situation in Iran and Afghanistan'], 21-34. Paris: Editions du CNRS.

Thierry, François. 1989. "Empire and Minority in China." In Minority Peoples in the Age of Nation-States, ed. Gérard Chaliand, 76-99. London: Pluto Press.

Wallman, SAndra, ed. 1979. Ethnicity at Work. London: Macmillan Press.

Watson, James L. 1988. "Funeral Specialists in Cantonese Society: Pollution, Performance, and Social Hierarchy." In Death Ritual in Late Imperial and Modern China, eds. James L. Watson and Evelyn S. Rawski, 109-34. Berkeley: University of California Press.

Watson, James L., and Evelyn S. Rawski, eds. 1988. Death Ritual in Late Imperial and Modern China. Berkeley: University of California Press. 
Watson, Rubie S. 1988. "Remembering the Dead: Graves and Politics in Southeastern China." In Death Ritual in Late Imperial and Modern China, eds. James L. Watson and Evelyn S. Rawski, 203-27. Berkeley: University of California Press.

Wicker, Hans-Rudolf. 1997. "Introduction: Theorizing Ethnicity and Nationalism." In Rethinking Nationalism and Ethnicity: The Struggle for Meaning and Order in Europe, ed. Hans-Rudolf Wicker, 1-42. Oxford: Berg.

Yi Zhongtian. 2002. Fangyan yu wenhua. Xibei feng dongnan yu ["Dialect and culture" series. In the northeast it is windy, in the southeast it rains]. Shanghai: Shanghai Wenhua Chubanshe. 